\title{
WATGIS: A GIS-BASED LUMPED Parameter Water Quality MODel
}

\author{
G. P. Femandez, G. M. Chescheir, R. W. Skaggs, D. M. Amatya
}

\begin{abstract}
ABSTRACr. A Geographic Information System (GIS)-based, lumpedparameter water quality model was developed to estimate the spatial and temporal nitrogen-loadingpatterns for lower coastal plain watersheds in eastern North Carolina. The model uses a spatially distributed delivery ratio (DR) parameter to accountor nitrogen retention or loss along a drainage network. Delivery ratios are calculatedfrom time of travel and an exponential decay model for in-stream dynamics. Travel times from any point in the drainage network to the watershed outlet are obtained from simulations using a combined physically based field hydrology and drainage canal routing model (DRAINMOD-DUFLOW). Nitrogen load from contributing areas in the watershed delivered to the main watershed outlet is obtained as the product of field export with the corresponding delivery ratio. The total watershed load at the outlet is the combined loading of the individual fields. Nitrogen exports from source areas are measured. The lumped water quality model is integrated within a GIS framework with menu interface, display options, and statistical procedures. Within this framework, the model can be used as a screening tool to analyze the effects of different land and water management practices on downstream water quality. A description of the model is presented along with the results from the evaluation of the model to characterize the seasonal and annual export of nitrogen from a drained forested watershed near Plymouth, North Carolina. Results of the study showed that the lumped parameter model can reasonably predict the loads at the outlet of the watershed. Predicted loads for 1997 were highly correlated with the observed loads (correlation coefficients of 0.99, 0.90, and 0.96 for nitrate-nitrogen, TKN, and total nitrogen respectively). Sensitivity and uncertainty analyses indicated that predicted outlet loads were sensitive to field flow predictions and export concentrations. Overall, the results indicate that the lumped parameter model can be an effective tool for describing the monthly nitrogen loads from a poorly drained coastal plain watershed.
\end{abstract}

Keywords. DRAINMOD, Hydrology, Water quality.

$\mathrm{E}$ valuation of the cumulative effects of land use and water management practices on downstream hydrology and water quality of a watershed requires consideration of many factors including climate, geology, soils, vegetation cover, and soil and water management practices. The interaction of these factors is complex; computer simulation models provide a means of integrating contributions from each of them. The spectrum of models used for water quality planning and assessment range from the more comprehensive process-based models such as WASP4 (Ambrose et al., 1981), QUAL2E (EPA, 1987), HSPF (Johanson et al., 1981), DUFLOW (Aalderlink et al., 1995), and CE-QUAL-RIVl (Dortch et al., 1990) to the conceptual and/or highly simplified lumped parameter models (Haith and Shoemaker, 1987; Reckhow et al., 1992; Johnes, 1996). Complex models are capable of simulating the impacts of the dynamics of natural processes in large

\footnotetext{
Article was submitted for review in January 2001; approved for publication by the Soil \& Water Division of ASAE in November 2001.

The authors are Glenn P. Fernandez, ASAE Member Engineer, Research Associate; George M. Chescheir, ASAE Member Engineer, Research Assistant Professor, R. Wayne Skaggs, ASAE Fellow Engineer, W.N.R. Distinguished University Professor; and Devendra Amatya, ASAE Member Engineer, Research Assistant Professor, Biological and Agricultural Enqineering Department. North Carolina State University. Raleigh, North Carolina. Corresponding author: Glenn Femandez, 182 Weaver Lab, Box 762.5, North Carolina State Univ., Raleigh, NC 27695; phone: 9 19-5 IS-67 14; e-mail: gfemand@eos.ncsu.edu.
}

watersheds on a shorter time scale. However, as decision tools for planners, they are difficult to use due to their high input data requirements, problems in calibration in large watersheds, and parameterization. In addition, the underlying uncertainties in the formulation of processes and parameterization often contribute to uncertainties in predictions (Beck, 1987). In most cases, the choice of a model depends upon the user's knowledge of the model, data availability, the system where it is applied, and the desired application. Most decision makers working with watershed-level management may only need planning-level information. This could be obtained easily from the use of lumped parameter models, which require minimal input data to run and are capable of accurate predictions on longer time scales (Cooper and Bottcher, 1993). When coupled with error and uncertainty analyses, lumped parameter models can provide decision makers with more information than the traditional deterministic output. Moreover, the time and effort needed to run these models are considerably less than what is required in using physically based models.

Through research conducted on the coastal plain soils over the years (Skaggs and Gilliam, 1981; Gilliam and Skaggs, 1986; Amatya et al., 1998), the magnitude of nutrient losses (N and P) from agricultural and forested lands and the factors affecting these losses have been determined under various water management (e.g., controlled drainage) and nutrient management practices. Recent studies by Birgand (2000) have characterized the in-stream processes occurring in agricultural ditches and canals of lower coastal plain 
watersheds. Models for predicting nutrient losses at the field edge such as DRAINMOD-N, a version of DRAINMOD that considers nitrogen balance, have also been developed and tested on poorly drained soils (Breve et al., 1992; Skaggs et al., 1995a, 1995b). Results of these past studies can be used to estimate the nutrient exports needed for a watershed-scale lumped parameter model. Mechanistic DRAINMOD-based watershed-scale models coupled with canal routing components have also been developed, and studies indicated that the integrated models are capable of simulating the hydrology of poorly drained coastal watersheds (Amatya et al., 1999; Fernandez et al., 1997).

This article describes the development and evaluation of a watershed-scale lumped parameter water quality model for approximating in-stream processes that affect nitrogen loading at the outlet of poorly drained lower coastal plain watersheds. The framework for using a mechanistic hydrology and hydraulics model to predict travel times and, subsequently, delivery ratios for nitrogen loads from source areas within the watershed to the watershed outlet is described. In addition, the model uses a GIS framework to allow ease of use and to facilitate the pre- and post-processing of inputs and modeling results.

\section{MODELING APPROACH}

The modeling approach assumes that the net loss in nutrients and sediment loads as drainage water moves from source areas to the watershed outlet is exponentially dependent on time in transit and can be described with a single attenuation coefftcient for each constituent. The nutrient and sediment loads delivered to the outlet of a watershed are predicted with an empirically determined attenuation coefficient (decay rate). The model is expressed as:

$$
L=\Sigma D R_{i} * L_{o i}, i=1 \ldots n \text { and } D R_{i}=\exp \left(-k t_{i}\right)
$$

w h e r e

$L=$ nutrient load at the outlet $(\mathrm{kg} / \mathrm{ha})$

$D R_{i}=$ delivery ratio $(\%)$ for source area $i$

$L_{o i}=$ export coefficient for the source area $i(\mathrm{~kg} / \mathrm{h})$

$k=$ empirically determined attenuation coefficient (1/day)

$t_{i}=$ time-of-travel of drainage water from source area $\boldsymbol{i}$ to the outlet (day).

$L_{o i}$ can be expressed as the product of $Q_{i}$ and $C_{i}$, which are the outflow and corresponding nutrient concentration from the source area $i$, respectively.

The delivery ratio is intended to integrate the in-stream transformations and transport characteristics that occur as the nutrients are transported from the source areas to the watershed outlet. Among other factors, the delivery ratio depends on the time-of-travel along the drainage network and the attenuation coefftcient (Birgand, 2000). It approximates the transformations and losses of nutrient along the drainage network. This model-differs from the conventional export coefficient approach (e.g., Johnes, 1996) since it considers the attenuation of the nutrients along the hydrologic pathways. Accuracy and uncertainty of the predictions at the watershed outlet depend on the uncertainties of estimating the source loading, attenuation coefficient, and the travel time. They also depend on the validity of the hypothesis that the relevant processes can be described by a simple exponential decay function.

An important factor that determines the delivery ratio is the time of travel along the stream network. The general procedure for determining time of travel is to conduct tracer experiments along a stream network by observing the variation in concentrations of the tracer as it moves downstream (Jobson, 1997). The time of travel can also be estimated by conducting simulation studies using a mechanistic hydraulics and water quality model. For coastal plain watersheds, the DRAINMOD-DUFLOW hydrology/hydraulics and water quality model (Femandez et al., 1997) or DRAINWAT (Amatya et al., 1999) can be used to estimate travel times. Both models simulate field hydrology using DRAINMOD and a numerical solution to the Saint Venant equations for hydraulic routing. A generalized model of the travel times as a function of hydraulic and watershed characteristics can be developed.

The lumped parameter model described above requires the following inputs: (1) daily or monthly outflows and monthly mean daily export concentrations or loads from source areas, (2) a decay coefficient, and (3) time of travel along the drainage network. The model is designed to be flexible in terms of input requirements and subsequent applications. Output of the model consists of monthly nutrient loads at the watershed outlet and corresponding delivery ratios. For coastal plain watersheds, the DRAINMOD model can be used to estimate the daily outflows from contributing areas. The export concentrations or loads can be measured, estimated based on literature values, or simulated using a process-based field water quality model, such as DRAINMOD-N for coastal plain watersheds. For upland areas, field-scale hydrology and water quality models such as GLEAMS (Leonard et al., 1987), EPIC (Williams et al., 1985), or SWAT (Arnold et al., 1998) can be used to simulate field outflows and exports. In comparison to complex process-based models, use of the lumped parameter model described above as a decision tool for water quality assessments would require less time and effort.

The model described in this article is integrated within a Geographic Information System (GIS). The modeling system was developed using Visual Basic (Microsoft Corp.) and Map-Objects (Environmental System Research Institute, Inc). The GIS interface was developed to provide an interactive framework for preparing input data sets, editing and creating map layers (e.g., drainage network, soils and land use, computational nodes and reaches, and drainage areas), running simulations and performing uncertainty analysis, and visually presenting the results through graphs, tables, and maps. Figure 1 shows the interface with maps of the watershed, travel time, delivery ratios, and outlet loads.

\section{Methodology \\ Site D ESCRIPTION}

The lumped parameter water quality model described above was tested on a 2900 ha drained forested watershed (S4 sub-watershed in fig. 2). The watershed is located in the lower coastal plain in eastern North Carolina. The S4 watershed is part of a larger, intensively instrumented 10,000 ha mixed land use watershed. Both organic and mineral soils are present in the watershed. The drainage system of the 


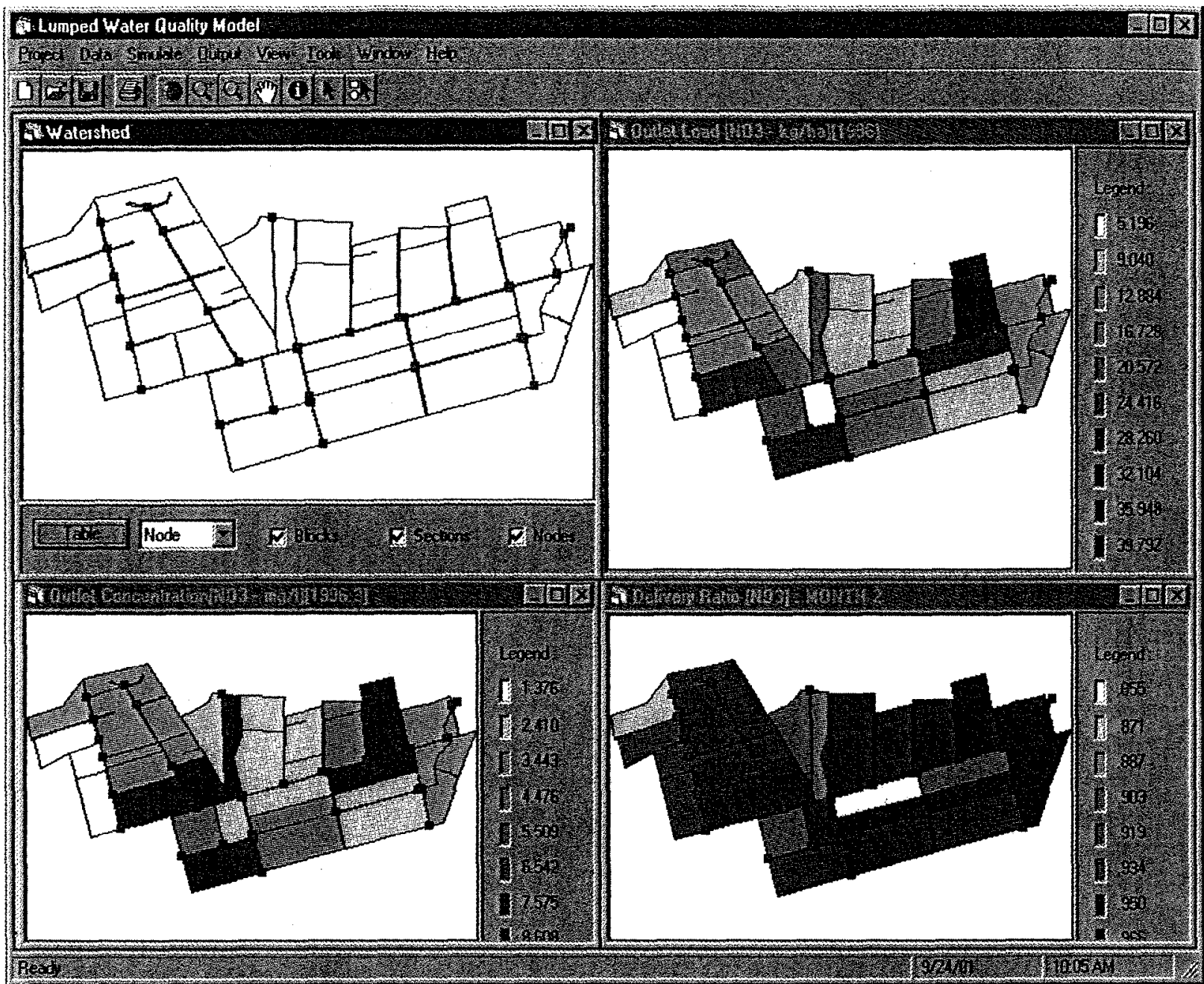

Figure 1. The watershed-scale lumped parameter water quality modeling system (WATGIS).

watershed consists of a network of field ditches generally 0.6 to $1.2 \mathrm{~m}$ deep and spaced $100 \mathrm{~m}$ apart. The field ditches flow to collector canals 1.8 to $2.5 \mathrm{~m}$ deep and spaced approximately $800 \mathrm{~m}$ apart that empty into main canals approximately 1.8 to $3.0 \mathrm{~m}$ deep. Surface cover is characterized by second growth mixed hardwood and pine forest and lobioiiy pine plantation of various ages and stages.

Hourly rainfall is measured at three stations on the S4 watershed. A complete weather station is located at field F6, approximately at the center of the watershed. Flow measurements are recorded and water quality of the drainage waters is sampled at several gauging and sampling stations within the watershed (fig. 2). The gauging stations are located at five field drainage outlets (F1, F3, F5, F6, and F7), three on the main drainage canals ( $\mathrm{Si}, \mathrm{S} 2$, and $\mathrm{S} 3$ ) and on the outlet of watershed (S4). Instrumentation at the automatic stations includes sharp-crested $120^{\circ} \mathrm{V}$-notch weirs, water level recorders, automatic samplers, and microprocessors to store data and control the sampleis. Field and canal sampling stations are serviced biweekly, at which time grab samples are also collected to determine water quality at ail stations. A more detailed description of the network of monitoring stations for both flow and water quality sampling for this sub-watershed and the larger watershed is presented in Chescheir et al. (1998).

\section{Simulation}

The watershed was divided into 27 fields, with the drainage network discretized into 46 segments consisting of 39 canal reaches and 7 weir control structures (fig. 1). Each field is assumed homogeneous with respect to soils, surface cover, and water management practices. Field areas, stream lengths, field and canal bed elevations, and dimensions of canals and weir control structures were obtained from field surveys and organized into GIS coverages and a database.

To account for the spatial variability of rainfall over the watershed, the rainfall measured at three stations (RI, R6, and $\mathrm{R} 8$ gages in fig. 2) within the watershed were distributed to the different fields using a "nearest neighbor" approach. The spatial distribution of rainfall over the watershed is intended to account for the observed gradient in annual rainfall from the western edge to the eastern part of the watershed. This trend parallels the orientation of the main drainage canal of the watershed (west to east drainage flow path).

In the absence of measured soil water characteristics for all the fields, properties of the dominant soil series for each 


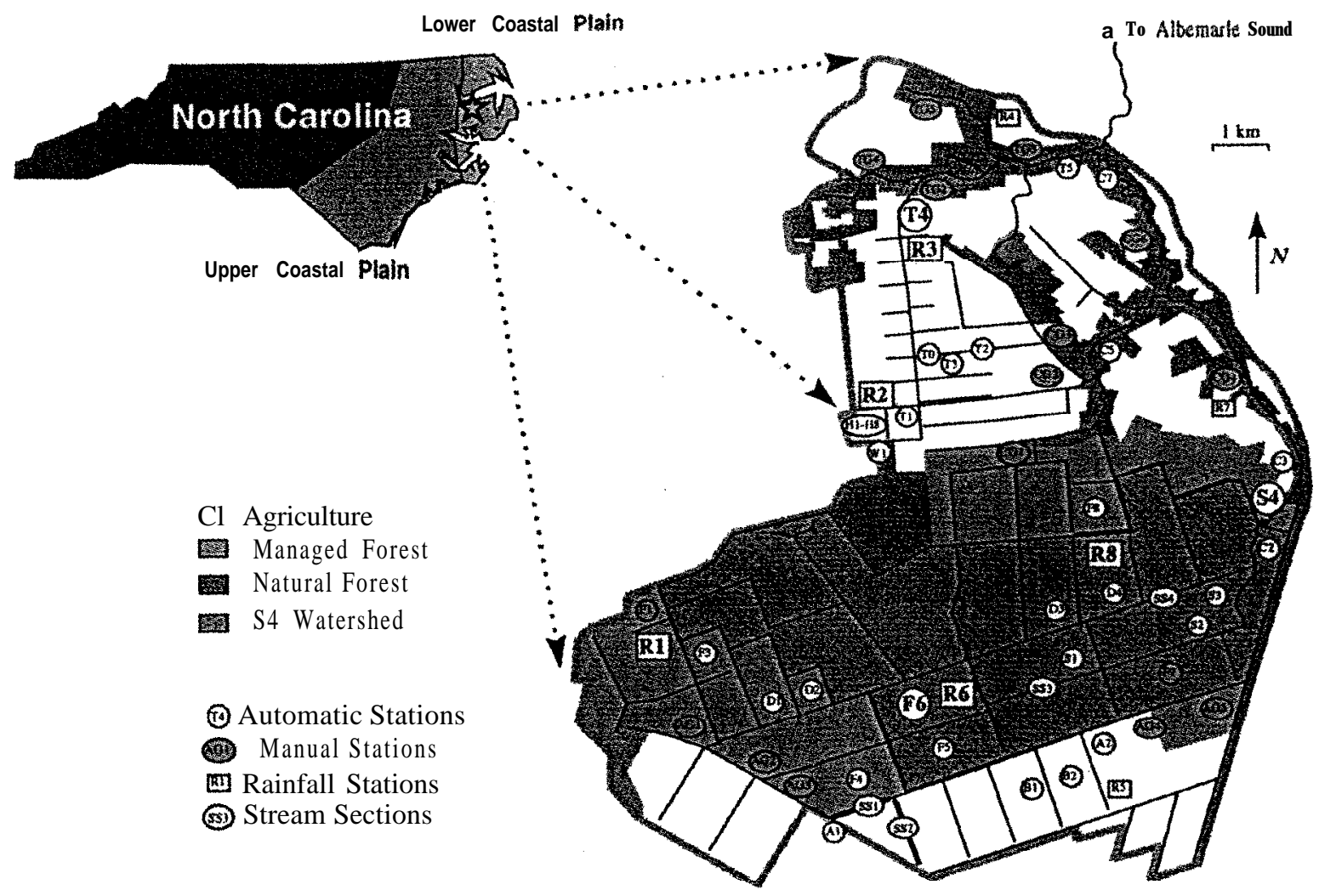

Figure 2. Diagram of study site near Plymouth, North Carolina.

field were obtained from published values, as reported in Skaggs and Nassehzadeh-Tabrizi (1986).

Daily outflows from each field were predicted by the DRAINMOD model. Using the predicted drainage outflows from each field, field loads were calculated as the product of the outflows and export concentrations. For each field, the load that was exported to the outlet of the watershed was determined by applying a delivery ratio (a function of travel time and decay coefficient) assuming an exponential decay function. Summing up the exported loads from each field produces the total watershed load.

Time-of-travel from each field outlet to the outlet of the watershed was determined from simulations using the DRAINMOD-DUFLOW model. The DRAINMOD-DUFLOW model was calibrated using the measured flow for 1996, and simulations using weather data for 1961-1990 were done to predict the travel times. Daily loads of a conservative tracer (e.g., chloride or another ion which is assumed to be non-reactive as it moves through the canal system) were routed from each field to the watershed outlet. Each field was simulated separately to determine its respective travel time. Loading response curves of the conservative tracer predicted at the outlet during the main flow periods were determined and summarized. Travel times, corresponding to the time when $50 \%$ of the input load arrives at the outlet, were obtained from the response curves. The travel times were related through nonlinear regression analysis to the discharge from the given field, the total drainage area upstream of the field, and the length of the flow path to the watershed outlet. The regression model was used to predict the travel times to determine the delivery ratios, given the decay coefficients.

The decay coefficients used were determined from calibration using the 1996 flow and nitrogen exports. The coefficients used were: 0.05 (fall-winter) and 0.1 (springsummer) for nitrate nitrogen, and 0.05 for TKN for all months. Total nitrogen was predicted as the sum of nitratenitrogen and TKN.

Water quality data collected from biweekly composite and grab samples from five experimental fields in the S4 watershed were used to generate the export concentrations for the individual fields. The data from the experimental fields were distributed to the. 27 fields in the watershed based on similarities in soil type, water management practice, stand age, and type of surface cover.

The model was calibrated using the flow and nitrate-nitrogen, TKN, and total nitrogen exports for 1996 and evaluated using the 1997 data. Monthly simulated flows and loads at the outlet were compared, and statistics of goodness-of-fit for the evaluation were determined using correlation and Nash-Sutcliffe coefficients.

\section{Sensitivity and UNCERTAINTY ANALysis}

The procedure for performing uncertainty analysis of the watershed-scale model follows that proposed by Haan and Skaggs (1999). Model parameters were identified that were the most sensitive and can have significant impact in quantifying the nitrogen loads at the watershed outlet. The uncertainty in predicting the outlet loads as a function of the uncertainties in estimating the field outflows, export con- 
centrations, decay coefficient, and travel times were investigated.

Statistics and the probability density functions for the field outflows and travel times were obtained from a 30-year simulation using the DRAINMOD-DUFLOW model. Statistical parameters for the export concentrations were obtained from the 1996-1997 measured data. Without the knowledge of the correlations of the parameters, it was assumed that the parameters have negligible correlations.

A Latin Hypercube Sampling (Salas and Shin, 1999) was used to generate random samples (300 samples) of the different field and network parameters. The objective function chosen was the annual cumulative nitrogen load at the watershed outlet. Results of the uncertainty analysis were summarized in the form of cumulative distribution of the objective function with corresponding confidence limits.

\section{Results AND Discussion}

One of the main objectives of the study was to determine the capability of the model to simulate the nitrogen loads from coastal plain watersheds.. Flow and nitrogen concentration data from 1996 were used for calibration, and data from 1997 were used for evaluation.

\section{Simulation RESUlts}

The temporal trend and magnitude of daily and monthly flows predicted by the DRAINMOD model is in good agreement with the observed flows at S4 (figs. 3 and 4). Over the IO-month calibration period, the predicted monthly flows were highly correlated with the measured flows ( $\mathrm{p}=$ 0.96). The Nash-Sutcliffe $\mathrm{R}^{2}$ value for the monthly data was 0.85 . On the average, the model over-predicts the monthly flow by $4.2 \mathrm{~mm}$ (over-mediction of $11 \%$ ). To a large extent. the over-prediction in 1996 was due to the over-prediction of peak flows during the occurrence of tropical storms (late summer to fall). For this period, the measured values were probably underestimated because the weir at the outlet was submerged. Moreover, since the outflows were not routed to the outlet (the sum of outflows for all fields is the total outlet flow), the model did not considering effect of in-stream control structures in modulating the flows in the network.

Measured and predicted monthly flow data for the evaluation period yielded a Nash-Sutcliffe coefficient of 0.84 and a correlation coefficient of 0.96 . On the average, the model under-predicted the monthly flows by $2.1 \mathrm{~mm}$ (under-prediction of 16\%). This under-prediction in 1997 can be attributed to errors in estimating watershed rainfall and/or PET during the late winter and spring. An event in late winter in 1997 was not predicted by the model.

Nonlinear regression of the simulated travel times as a function of upstream drainage area, length of the flow path, and mean daily outflows from the contributing area is shown in figure 5. The predicted travel times are highly correlated with the three factors described above $\left(\mathbf{R}^{2}=0.89\right)$.

The trend in the prediction of nitrogen loads at the watershed outlet was similar to the results for outflows (figs. 6-8). Over-prediction of outflows in 1996 resulted in over-prediction of total nitrate load by 1 1\%, over-prediction of TKN by $2 \%$, and over-prediction of total nitrogen by $7 \%$. Comparison of the monthly measured and predicted loads yielded Nash-Sutcliffe coefficients of $0.83,0.95$, and 0.90

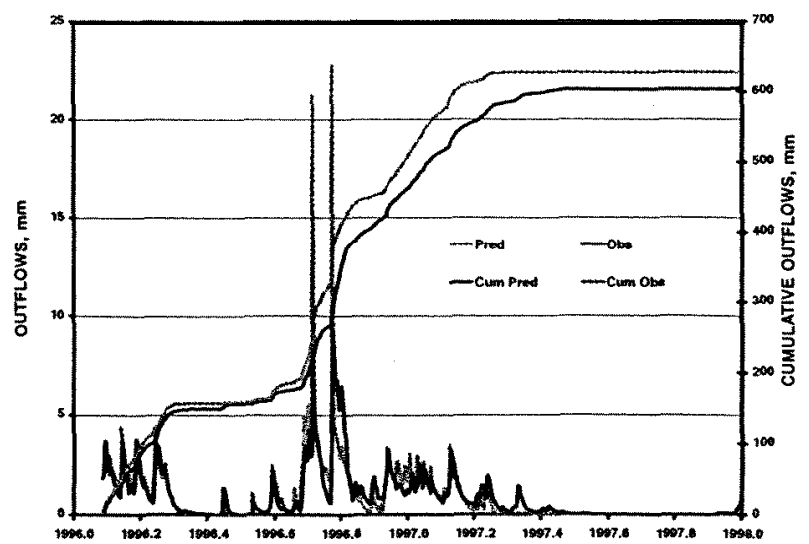

Figure 3. Measured and predicted daily outflows for $\mathbf{S 4}$ watershed for 23 months (February 1996 to December 1997).

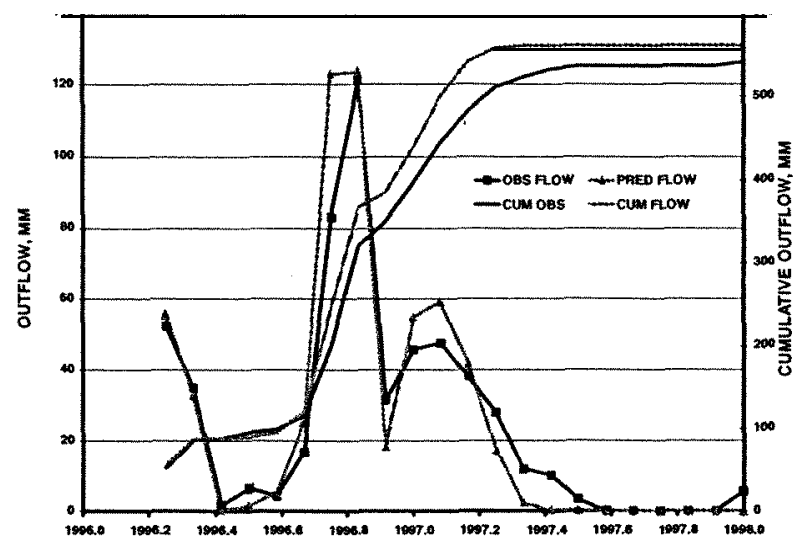

Figure 4. Measured and prediited monthly outflows for S4 watershed for 23 months (March 1996 to December 1997).

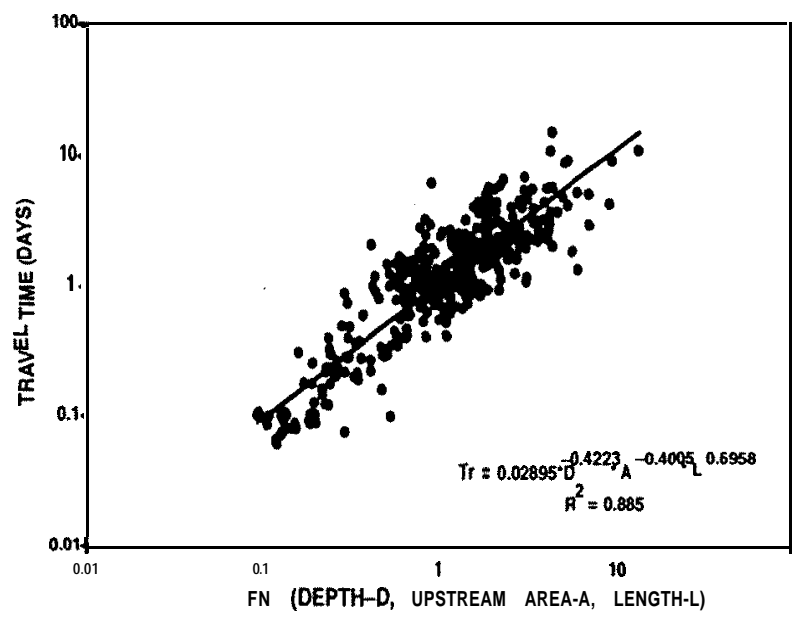

Figure 5. Time of travel as a function of mean daily outflow D (cm), total upstream drainage area $A$ (ha), and length of flow path $L(m)$.

and correlation coefficients of $0.96,0.98$, and 0.98 for nitrate-nitrogen, TKN, and total nitrogen loads, respectively. For the evaluation period, the under-prediction in outflows resulted in under-prediction of total nitrogen load by $3 \%$, over-prediction of TKN by $1 \%$, and under-prediction of nitrate-nitrogen by $11 \%$. The Nash-Sutcliffe coefficients were $0.98,0.14$, and 0.68 and the correlation coefficients 
were $0.99,0.90$, and 0.96 for nitrate-nitrogen, TKN, and total nitrogen respectively. Overall, the prediction errors for total watershed load for the 22 months were $8 \%$ for nitrate-nitrogen, $2 \%$ for TKN, and 5\% for total nitrogen. Errors in the prediction of the loads cannot be attributed solely to the errors in flow predictions. Errors in estimating export concentrations at the field edge would have contributed to the errors in the load predictions. Measured concentrations from five fields were extrapolated to the remaining 22 fields.

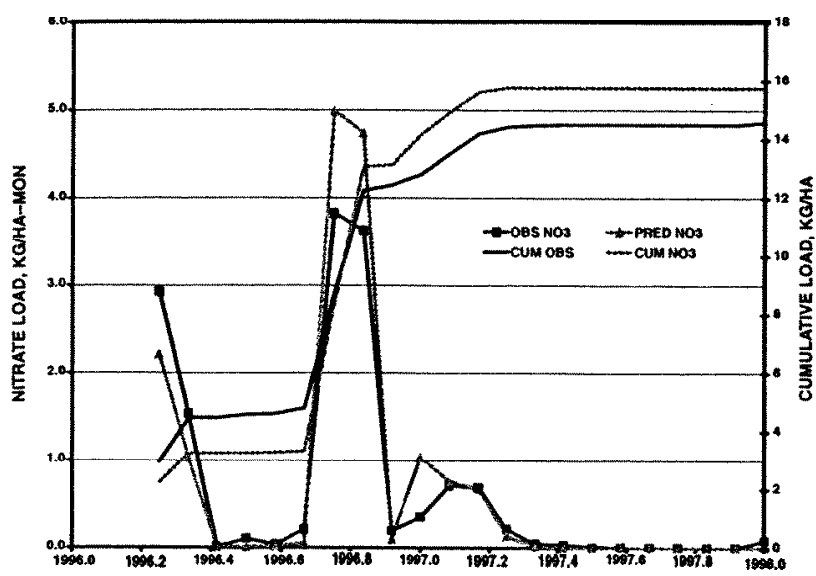

Figure 6. Measured and predicted nitrate-N for $\mathbf{S 4}$ watershed for 22 months (March 1996 to December 1997).

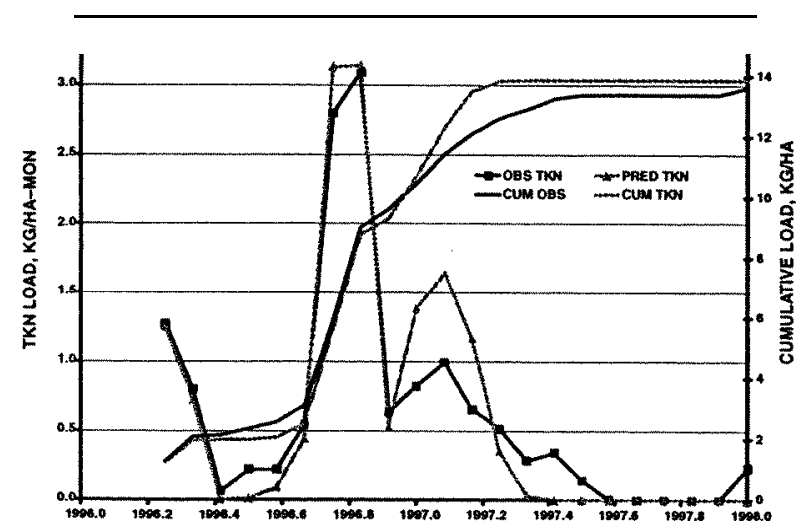

Figure 7. Measured and predicted TKN for $\mathrm{S} 4$ watershed for 22 months (March 1996 to December 1997).

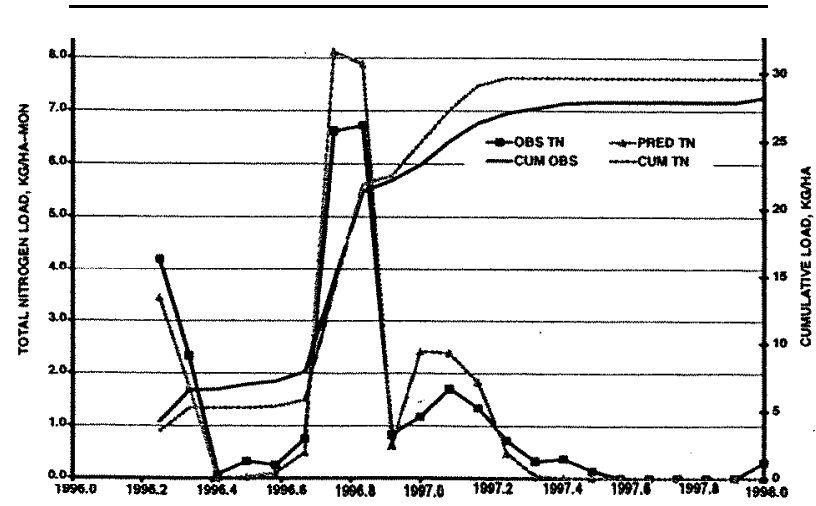

Figure 8. Measured and predicted total nitrogen for $\mathrm{S} 4$ watershed for 22 months (March 1996 to December 1997).
The dependence of the load predictions on outflows is expected. Outlet loads were calculated from export concentrations that were converted to equivalent load by multiplying with the mean flow for the given time period and attenuated with a delivery ratio. The dependence, though, is nonlinear since the delivery ratio is nonlinearly dependent on $k$ and $\boldsymbol{t}_{\boldsymbol{i}}$.

\section{Sensitivity and Uncertainty analysis}

Sensitivity analysis indicated that the predicted outlet load is highly sensitive to outflows $\left(Q_{i}\right)$ and field export concentrations $\left(C_{i}\right)$ and less sensitive to the decay coefficient (k) and time of travel $\left(t_{i}\right)$. The normalized sensitivity coefficient (Haan and Skaggs, 1999) calculated for both $Q_{i}$ and $C_{i}$ is $1 \%$, while fork and $\boldsymbol{t}_{\boldsymbol{i}}$ it is $0.04 \%$. These coefficients indicate that a $1 \%$ change in either $Q_{i}$ or $C_{i}$ will result in a corresponding $1 \%$ change in output load. On the other hand, a $1 \%$ change in either $k$ or $t_{i}$ will result in only $0.04 \%$ change in output load. Predictions of the total watershed load appear to be less sensitive to the choice of and $t_{i}$. However, the uncertainty of the model output is not directly related solely to the sensitivity of the parameters. A highly sensitive parameter that is known with certainty may have a much less impact on the total uncertainty of the mode 1 outputs than a much less sensitive parameter that is highly uncertain (Melching and Yoon, 1996).

An uncertainty analysis using a Latin Hypercube sampling (Salas and Shin, 1999) method was done on the field exports $\left(C_{i}\right)$, field outflows $\left(Q_{i}\right)$, decay coefficient $(\mathbf{k})$, and time of travel $\left(t_{i}\right)$. Results of the uncertainty analysis indicated that the variance of the outlet load due to the uncertainties in field outflows and export concentrations were higher than that due to the uncertainties of the decay and time of travel parameters. The confidence limits (at 95\%) of the mean annual outlet load due to the variability in field outflows and exports are higher than the limits for the decay and time of travel (fig. 9). The corresponding intervals are much wider. The uncertainty in exports produces a much wider confidence interval than the interval for field outflows.

Although the analysis indicated that the model is less sensitive to the choice of the decay coefficient, this parameter is probably the most uncertain. The parameter integrates the rates of the processes that describe the cycling of the nutrient within the stream network. Time of travel and flow rates can be reliably predicted with integrated watershed-scale models such as the DRAINMOD-based models (Amatya et al., 1999; Femandez et al., 1997). Nutrient exports and concentrations from poorly drained soils under various water and nutrient management practices can be reasonably determined from field and/or modeling studies.

\section{Summary and Conclusion}

A watershed-scale lumped parameter water quality model integrated within a GIS framework (fig 1) was developed and tested using two years of hydrology and water quality data from a 2900 ha forested watershed in eastern North Carolina. The water quality model uses a spatially distributed delivery ratio to approximate in-stream processes as the nutrient is transported from source areas to the watershed outlet. The delivery ratio is dependent on time of travel along the 


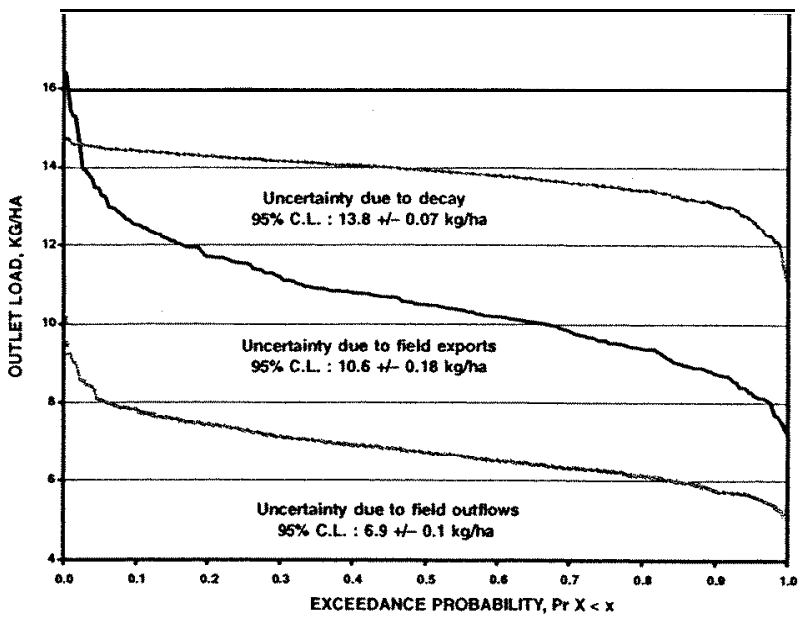

Figure 9. Uncertainty in average annual nitrate-nitrogen load at the watershed outlet due to variability in field outflows, export concentrations, and decay coeffkient.

drainage network and on an attenuation coefficient. Results of the evaluation of the model showed that reasonable and accurate prediction of the nutrient loads delivered to the outlet of the watershed requires accurate predictions of the hydrology and hydraulics of the system, characterization of the attenuation of the nutrients in the drainage network, and estimation of the field exports. Statistics of goodness-of-fit showed the model can adequately predict the nitrogen loads at the outlet of the test watershed.

Using simulations with the DRAINMOD-DUFLOW model, a model for predicting the travel times as a function of mean daily outflow and total upstream drainage area of the contributing areas and the length of the flow path was developed. The model was used to determine travel times for use in the lumped parameter model. The model for the travel times would be useful for routine application (multiple "what if' scenarios) of the lumped parameter model. Detailed simulations using a mechanistic model is not needed if a generalized function for predicting travel times is developed.

Sensitivity and uncertainty analyses indicated that predicted outlet loads are most sensitive to field flow predictions and export concentrations. Although model predictions are not very sensitive to the attenuation coefficient, the uncertainty in estimating this parameter affects the overall uncertainty of the model predictions. This coefficient lumps all the processes that would otherwise describe the in-stream cycling of the nutrient along the drainage network.

\section{ACKNowledgements}

This work was supported by the U.S. EPA 319 Program, USDA-CREES NRI Project 98-35 1024493, North Carolina Water Resources Institute, and Weyerhaeuser Company. The authors would like to acknowledge the contributions of Joe Hughes, Martin Lebo, Sandra McCandless, Joe Bergman, and Cliff Tyson of Weyerhaeuser Company, and Francois Birgand, Wilson Huntley, and Jay Frick of North Carolina State University.

\section{REFERENCES}

Aalderink, R. H., N. J. Klaver, and R. Noorman. 1995. DUFLOW V2.0 Microcomputer package for the simulation of I-dimensional flow and water quality in a network of open channel courses. In Proc. International Symposium on Water Quality Modeling, 416-425. Orlando, Fla. St. Joseph, Mich.: ASAE.

Amatya, D. M., J. W. Gilliam, R. W. Skaggs, M. E. Lebo and R. G. Campbell. 1998. Effects of controlled drainage on water quality. J. Environmental Quality 27(4): 923-935.

Amatya, D. M., G. M. Chescheir, G. P. Femandez, and R. W. Skaggs. 1999. Testing of a watershed-scale hydrologic/water quality model for poorly drained soils. ASAE Paper No. 992070. St. Joseph, Mich.: ASAE.

Ambrose, R. B., T. A. Wool, J. L. Martin, J. P. Connolly, and R. W. Schanz. 198 I. WASP4: A hydrodynamic and water quality model. Model Theory, User's Manual, and Programmer5 Guide. Athens, Georgia: U.S. EPA.

Arnold, J. G., R. Srinivasan, R. S. Muttiah, and J. R. Williams. 1998. Large-area hydrologic modeling and assessment: Part I. Model development. J. Am. Water Resourc. Assoc. 34(I): 73-89.

Beck, M. B. 1987. Water quality modeling: A review of the analysis of uncertainty. Water Resources Research 223(8): 1393-1442.

Birgand, F. 2000. Quantification and modeling of in-stream processes in agricultural canals in the lower coastal plain. Unpubl. PhD diss. Raleigh, N.C.: North Carolina State University.

Breve, M. A., R. W. Skaggs, H. Kandil, J. E. Parsons, and J. W. Gilliam. 1992. DRAINMOD-N: A nitrogen model for artificially drained lands. In Proc. 6th National Drainage Symposium, 327-336. Nashville, Tenn. St. Joseph, Mich.: ASAE.

Chescheir, G. M., D. M. Amatya, G. P. Femandez, R. W. Skaggs, and J. W. Gilliam, 1998. Monitoring and modeling the hydrology and water quality of a lower coastal plain watershed. In Proc. 1998 Water Management Specialty Conference, 2 15-222. Denver, Colo. May 3-6, 1998. Alexandria, Va.: Water Environment Federation.

Cooper, A. B., and A. B. Bottcher. 1993. Basin-scale modeling as a tool for water resource planning. $A S C E J$. Water Resources Planning and Management I 19(3): 306-323.

Dortch. M. S., T. Schneider, J. Martin, M. Zimmerman, and D. M. Griffin. 1990. CE-QUAL-RIV 1: A dynamic, one-dimensional water quality model for streams. User's Manual. Instruction Report E-90-1. Vicksburg, Miss.: U.S. Army Engineer Waterways Experiment Station.

EPA. 1987. The enhanced stream water quality models QUAL2E and QUAL2E-UNCAS. Document and User's Manual. EPA/600/3-87/007. Athens, Georgia: U.S. EPA.

Femandez, G. P., G. M. Chescheir, R. W. Skaggs, D. M. Amatya, F. Birgand, and J. W. Gilliam. 1997. Development and field testing of a DRAINMOD-based watershed-scale model. ASAE Paper No. 972194. St. Joseph, Mich.: ASAE.

Gilliam, J. W., and R. W. Skaggs. 1986. Controlled agricultural drainage to maintain water quality. J. Irrig. Drain. Eng. I 12(3): 2.54-263.

Haith, D. A., and L. L. Shoemaker. 1987. Generalized watershed loading functions for stream flow nutrients. Water Resources Bulletin 23(3): 471-478.

Haan, P. K., and R. W. Skaggs. 1999. Effect of parameter uncertainty on DRAINMOD hydrologic and yield predictions. ASAE Paper No. 992163. St. Joseph, Mich.: ASAE.

Jobson, H. E. 1997. Predicting travel time and dispersion in rivers and streams. J. Hydraulic Eng. 123( I I): 971-978.

Johanson, R. C., J. C. Imhoff, H. H. Davis, J. L. Kittle, and A. S. Donigian. 198 1. Hydrologic Simulation Program, Fortran (HSPF). Release 7.0. User's Manual. Athens, Georgia: U.S. EPA. 
Johnes, P. J. 1996. Evaluation and management of the impact of land use change on the nitrogen and phosphorus load delivered to surface waters: The export coefficient modeling approach. J. Hydrology 183(3-4): 321-347.

Leonard, R. A., W. G. Knisel, and D. A. Still. 1987. GLEAMS: Groundwater loading effects of agricultural management systems. Trans. ASAE 30(5): 1403-14 18.

Melching, C. S., and C. G. Yoon. 1996. Key sources of uncertainty in QUAL2E model of Passaic River. J. Water Resources Planning and Management 122(2): 105-I 13.

Reckhow, K. H., S. Coffey, S. H. Henning, K. Smith, and R. Banting. 1992. EUTROMOD: Technical guidance and spreadsheet models for nutrient loading and lake eutrophication. Draft report. Durham, N.C.: Duke University, School of Environment.

Salas, J. D., and H. Shin. 1999. Uncertainty analysis of reservoir sedimentation. J. Hydraulic Eng. 125(4): 339-350.
Skaggs, R. W., and J. W. Gilliam. 1981. Effect of drainage system design on nitrate transport. Trans. ASAE 24(4): 929-934,940.

Skaggs, R. W., and A. Nassehzadeh-Tabrizi. 1986. Design drainage rates for estimating drain spacings in North Carolina. Trans. ASAE 29(6): 163 I-1640.

Skaggs, R. W., M. A. Breve, A. T. Mohammad, J. E. Parsons, and J. W. Gilliam. 1995a. Simulation of drainage water quality with DRAINMOD: Irrigation and Drainage Systems 9(3): 259-277. Dordrecht, The Netherlands: Kluwer Academic Publishers.

Skaggs, R. W., M. A. Breve, and J. W. Gilliam. 1995b. Predicting effects of water table management on loss of nitrogen from poorly drained soils. European J. Agronomy 4(4): 441-45 1.

Williams, J. R., A. D. Nicks, and J. G. Arnold. 1985. SWRRB: A simulator for water resources in rural basins. ASCE J. Hydrof. Eng. 11I(6): 970-986. 